\title{
Can First-trimester AST to Platelet Ratio Index Scores Predict HELLP Syndrome?
}

\author{
Harun Egemen Tolunay, Neval Cayonu Kahraman, Erol Nadi Varli, Yildiz Akdas Reis, Sevki Celen and Ali Turhan \\ Caglar \\ Perinatology Clinic, Etlik Zubeyde Hanim Maternity \& Women's Health Teaching and Research Hospital, Ankara, Turkey
}

\begin{abstract}
Objective: To determine whether the ratio of the first-trimester aspartate aminotransferase (AST) to platelet ratio index (APRI) score will be useful as a new determinant of hemolysis, elevated liver enzymes, low platelets (HELLP) syndrome that may develop in the later stages of pregnancy

Study Design: Descriptive-analytical study.

Place and Duration of Study: Perinatology Clinic of Etlik Zübeyde Hanım Maternity and Women's Health Teaching and Research Hospital, Ankara, Turkey. The data of patients diagnosed as having HELLP syndrome between 2018 and 2020 were analyzed retrospectively.

Methodology: Forty-two pregnant women with HELLP syndrome as the study group and 74 pregnant women with no morbidities as the control group were included in the study. First-trimester APRI scores were compared for both the groups. A characteristic curve (ROC) analysis of the study was performed to determine the APRI score levels predicting HELLP syndrome.

Results: One hundred and sixteen women with HELLP syndrome had significantly lower fibrinogen levels and platelet (PLT) levels than women without HELLP syndrome $(p<0.001)$. Women with HELLP syndrome had significantly higher ALT, AST, creatinine, and INR levels. These differences were significantly different $(p<0.001)$. Women who developed HELLP syndrome in the third trimester of pregnancy had significantly higher first-trimester APRI scores $(0.64 \pm 0.10)$ than the control group $(0.40 \pm 0.12$, $\mathrm{p}<0.001)$. In the ROC analysis, 0.55 as a cut-off value for first-trimester APRI scores had a sensitivity of $88.1 \%$ and a specificity of $94.6 \%$ for predicting HELLP syndrome developing in the third trimester of pregnancy.

Conclusion: There was an association of first-trimester APRI scores with the prediction of HELLP syndrome, possibly developing in the later weeks of pregnancy. Predicting HELLP syndrome in the early period can assist in proper management and taking necessary precautions.
\end{abstract}

Key Words: HELLP syndrome prediction, First-trimester APRI, APRI scores in pregnancy, APRI score.

How to cite this article: Tolunay HE, Kahraman NC, Varli EN, Reis YA, Celen S, Caglar AT. Can First-trimester AST to Platelet Ratio Index Scores Predict HELLP Syndrome?. J Coll Physicians Surg Pak 2021; 31(02):188-192.

\section{INTRODUCTION}

HELLP syndrome is characterized by hemolysis, increased liver enzymes, and low platelet count. This syndrome occurs in $0.5-0.9 \%$ of all pregnancies and is in the preeclampsia disease spectrum, featuring $10-20 \%$ of severe preeclampsia cases. In addition, HELLP syndrome progresses dramatically during pregnancy and can lead to fatal complications such as brain edema, multi-organ failure, and hepatic rupture. The mortality rate is 23.1-56.3\% for the mother and fetus. ${ }^{1,2}$ Thus, it is very important to estimate the probability of developing this disease in the first trimester of pregnancy.

Correspondence to: Dr. Erol Nadi Varl, Perinatology Clinic, Etlik Zubeyde Hanim Maternity and Women's Health Teaching and Research Hospital, Ankara, Turkey E-mail: e-nadi@hotmail.com

Received: July 25, 2020; Revised: August 24, 2020;

Accepted: September 08, 2020

DOI: https://doi.org/10.29271/jcpsp.2021.02.188
The previous studies used pregnancy-associated plasma protein-A (PAPP-A) and free beta-human chorionic gonadotropin ( $\beta$-HCG) as biochemical markers in the blood. Patients' ethnic origin, previous preeclampsia, and HELLP syndrome history, and patients' mean arterial pressure values to predict the onset of HELLP syndrome in the later weeks of pregnancy. ${ }^{3}$

The ratio of the enzyme aspartate aminotransferase (AST) to the platelet count index (APRI) in the blood is a traditional method in liver cirrhosis to recognize fibrosis in the liver. Today, it has been shown that the APRI scores in predicting HELLP syndrome are more valuable than AST values in the blood. ${ }^{4}$ However, there are no studies on whether HELLP syndrome can be predicted by looking at APRI scores in the first trimester.

Accordingly, in this study, the aim is to investigate whether APRI scores in the first-trimester could predict the HELLP syndrome in later pregnancy.

\section{METHODOLOGY}

This cross-sectional, descriptive-analytical single-center study 
was conducted at the Perinatology Clinic of Etlik Zübeyde Hanım Maternity and Women's Health Teaching and Research Hospital, Ankara, Turkey. In this study, patients who were diagnosed as having HELLP syndrome between 2018 and 2020 comprised the case group. Age and body mass index (BMI)-matched healthy pregnant women at similar pregnancy trimesters were recruited as the control group. Forty-two women with HELLP syndrome and 74 women with no morbidities were enrolled in the study. The approval of the local Ethics Committee was obtained for the study.

Clinical data related to the pregnant women aged at least 18 years who presented to the Perinatology Clinic with various symptoms and were diagnosed as having HELLP syndrome were retrospectively evaluated. HELLP diagnosis was made as recommended by the American College of Obstetricians and Gynecologists. ${ }^{5}$ Data including age, laboratory values (complete blood count, biochemical values, hepatitis markers, and liver enzymes) recorded from the computerized system of the hospital were analyzed. The control group was randomly selected from age and body mass index (BMI)-matched healthy pregnant women. Pregnant women in the control group were selected from patients without maternal hypertension, concomitant vasculardiseases, kidney diseases, diabetes mellitus, hematologic diseases, and autoimmune diseases. Patients aged below age 18 years, those with additional liver pathologies, women with intrahepatic cholestasis of pregnancy (IHCP), and patients whose data could not be accessed from the system were also excluded from the study.

The First-trimester hemogram parameters of the pregnant women were examined. The evaluated hemogram parameters consisted of blood samples taken in the routine first-trimester examination when the women presented to the hospital for routine pregnancy checks. AST and platelet values are part of the routine hemogram and biochemical tests. The APRI score was calculated by dividing AST by the platelet count. AST values in the blood are proportional to the number of platelets in the blood, and the APRI score is obtained. The first-trimester APRI scores of both groups were compared.

The Statistical Package for the Social Sciences (SPSS) version 20.0 for Windows software was used for all statistical analyses. Non-parametric tests and parametric tests were used according to the results of normality tests. Quantitative data were expressed as mean \pm S.D and Median (IQR). An independent samplest-test was performed to compare continuous variables when the normality tests met the criteria. The MannWhitney U-test was performed to compare the other dependent variables between patients with and without HELLP syndrome in the event that independent t-test assumptions were not met. P-values $<0.05$ were considered to be statistically significant.

Receiver operating characteristics (ROC) curve analysis was performed to determine the sensitivity and specificity of APRI scores in the prediction of HELLP syndrome.

\section{RESULTS}

As seen in Table I, pregnant women with HELLP syndrome had significantly lower fibrinogen levels (mean $=309.57 \pm 82.68$ ) than pregnant women without HELLP syndrome $($ mean $=481.01$ $\pm 87.85 \mathrm{mg} / \mathrm{dL}, \mathrm{p}<0.001$ ). However, the study group did not differ significantly from the control group in terms of mean age and gravida status ( $p>0.05)$. Women with HELLP syndrome had significantly lower PLT levels than women in the control group $(p<0.001)$. Women in the study group had significantly higher ALT and AST levels than women without HELLP syndrome $(p<0.001)$. Women with HELLP syndrome had significantly higher creatinine levels than women without HELLP syndrome $(p<0.001)$. Women in the study group had significantly higher INR levels than women without HELLP syndrome $(p=0.001)$. However, there were no differences in terms of the BMI, parity, and hemoglobin levels of the groups ( $p>0.05$ ).

An independent samples t-test was performed to compare the first-trimester APRI score of the patients. As seen in Table II, patients who developed HELLP syndrome in the later weeks of pregnancy had significantly higher first-trimester APRI scores (mean $=0.64 \pm 0.10$ ) than patients who did not develop HELLP syndrome in the later stages of pregnancy (mean $=0.40 \pm 0.12$, $\mathrm{p}<0.001$ ).

In the ROC analysis, the area under the curve (AUC) was 0.951; both visual inspection and the AUC value suggest that the fit of the model is acceptable to a very good range. The sensitivity was $88.1 \%$, and the specificity of the model was $94.6 \%$. The cutoff value corresponding to the point with the lowest distance to the upper-left corner of the ROC curve was 0.55 . Based on these criteria, the optimal cut-off value was 0.55 (Figure 1 ).

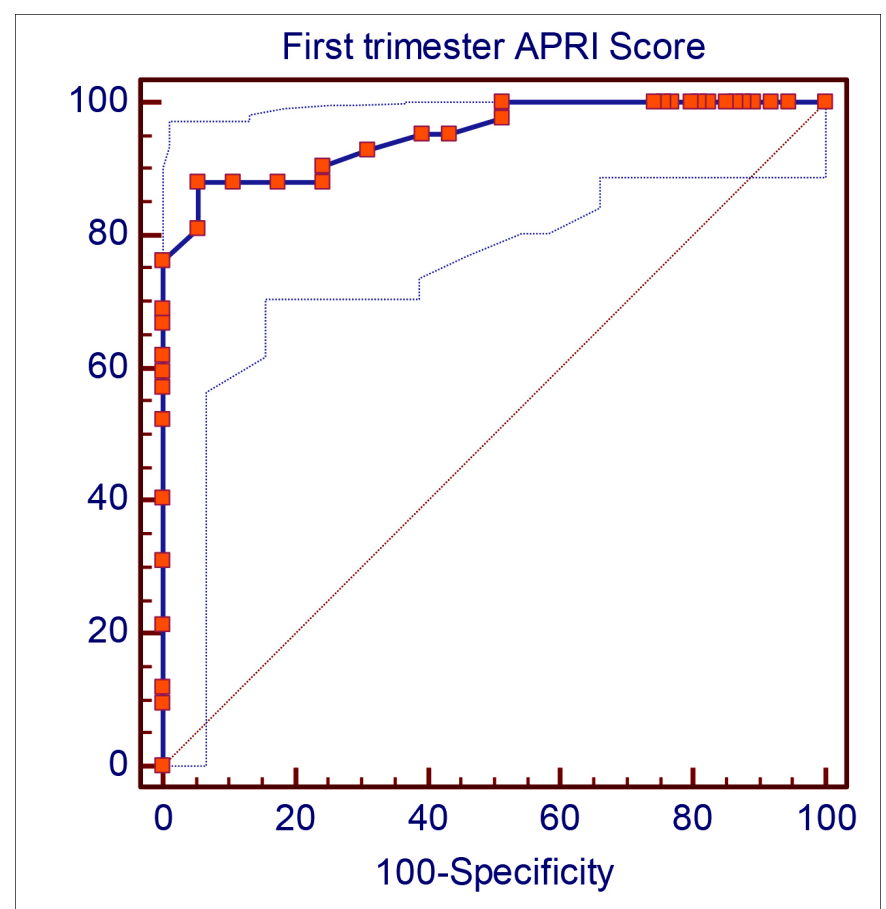

Figure 1: ROC analyse for first trimester APRI score to predict hellp syndrome. 
Table I: Baseline characteristics of the patients.

\begin{tabular}{|c|c|c|c|c|c|}
\hline \multirow[t]{2}{*}{ Variables } & \multicolumn{2}{|c|}{$\begin{array}{l}\text { Without HELLP }(n=74) \\
\text { Control Group }\end{array}$} & \multicolumn{2}{|c|}{$\begin{array}{l}\text { HELLP }(n=42) \\
\text { Study Group }\end{array}$} & \multirow[t]{2}{*}{ p-value } \\
\hline & Mean \pm SD & Median [Q1- Q3] & Mean \pm SD & Median [Q1- Q3] & \\
\hline Age (years) & $31.55 \pm 6.05$ & $30(30-32.5)$ & $30.76 \pm 5.16$ & $30(30-31)$ & $0.477^{*}$ \\
\hline Gravida & $2.95 \pm 0.96$ & $3(2-3)$ & $2.74 \pm 0.94$ & $3(2-3)$ & $0.262^{*}$ \\
\hline Parity & $1.93 \pm 0.96$ & $2(1-2)$ & $1.71 \pm 0.92$ & $1(1-2)$ & $0.173^{* *}$ \\
\hline BMI & $23.72 \pm 4.03$ & $23(22-26)$ & $23.69 \pm 4.41$ & $23(21.75-26.00)$ & $0.919 * *$ \\
\hline Hemoglobin & $11.11 \pm 1.26$ & $10.70(10.70-11.13)$ & $11.00 \pm 1.23$ & $10.70(10.70-11.13)$ & $0.823^{* *}$ \\
\hline Platelet Count & $237.76 \pm 87.14$ & $220(190-240)$ & $92.60 \pm 30.75$ & $89.50(70.00-102.75)$ & $<0.001^{* *}$ \\
\hline ALT & $27.34 \pm 13.08$ & $26(22-29)$ & $303.00 \pm 241.31$ & $200(150-456)$ & $<0.001^{* *}$ \\
\hline AST & $33.32 \pm 11.47$ & $32(30.00-36.50)$ & $267.05 \pm 287.88$ & $188(129-295)$ & $<0.001^{* *}$ \\
\hline Creatinine & $0.64 \pm 0.20$ & $0.60(0.59-0.76)$ & $1.01 \pm 0.48$ & $0.87(0.70-1.03)$ & $<0.001^{* *}$ \\
\hline Fibrinogen & $481.01 \pm 87.85$ & $468(434.00-514.50)$ & $309.57 \pm 82.68$ & $302(288-340)$ & $<0.001 *$ \\
\hline INR & $1.05 \pm 0.23$ & $1.00(1.00-1.10)$ & $1.18 \pm 0.30$ & $1.08(1.05-1.21)$ & $0.001 * *$ \\
\hline
\end{tabular}

Table II: First trimester APRI score according to patient groups.

\begin{tabular}{|l|c|c|c|c|c|}
\hline Variables & \multicolumn{2}{|c|}{ Without HELL $(\mathbf{n = 7 4 )}$} & \multicolumn{2}{c|}{ HELP (n=42) } & p-value \\
\hline First trimester APRI score & Mean \pm SD & Median [Q1-Q3] & Mean \pm SD & Median [Q1-Q3] & $0.65(0.59-0.69)$ \\
\hline
\end{tabular}

\section{DISCUSSION}

The findings of this study showed an association of firsttrimester APRI scores with predicting HELLP syndrome that may develop later in pregnancy. In our study, it was shown that the APRI score in the first trimester could predict the development of HELLP syndrome later in pregnancy. The value of 0.55 as the first-trimester APRI cut-off value in order to estimate the prediction of HELLP syndrome was evaluated in this study. The sensitivity as $88.1 \%$, and specificity as $94.6 \%$. The aim was to evaluate first-trimester APRI scores in the prediction of HELLP syndrome developing later in pregnancy because there was no such study in the literature.

HELLP syndrome can result in complications such as lifethreatening placental abruption, pulmonary edema, acute respiratory distress, disseminated intravascular coagulation (DIC), cerebral hemorrhage, septic shock, acute renal failure, and hepatic hemorrhage due to hepatic rupture. ${ }^{6}$ Therefore, it is very important to be able to predict and recognize HELLP syndrome in early gestational weeks.

The frequency of HELLP syndrome ranges from $0.5 \%$ to $0.9 \%$ of pregnancies. It occurs in $75 \%$ of cases before birth and is usually seen between the $27^{\text {th }}$ and $30^{\text {th }}$ weeks of gestation. Approximately $10 \%$ of cases occur before the 27 th week of pregnancy, and $20 \%$ occur after the $37^{\text {th }}$ week of pregnancy. Thirty percent of HELLP syndrome cases can be seen postpartum, usually until the 7 th day postpartum. ${ }^{7-9}$

The APRI score is a non-invasive method that has been used in the diagnosis of cirrhosis in the liver for years. It was defined as a correct predictor of the degree of liver fibrosis of patients with hepatitis $\mathrm{C}$ virus (HCV). ${ }^{10}$ The score was first defined in a cohort study of 192 patients with HCV undergoing liver biopsy. APRI scores higher than three points were shown as a strong non-invasive marker for cirrhosis. ${ }^{11}$ When the literature related to APRI scores is examined, patients with hepatic resection and radiofrequency ablation with an APRI score of $\leq 0.5$ show survival similar to liver transplantation. $^{12}$

According to Weinstein, when the natural course of HELLP syndrome is examined, thrombocytopenia is the first finding, then liver enzymes increase, and hemolysis is seen as the final stage. In $25 \%$ of cases, this syndrome can occur in the postpartum period. ${ }^{13}$

In HELLP syndrome, aggregation, activation, and peripheral consumption of platelets are impaired with endothelial damage, which causes thrombocytopenia. In preeclampsia and gestational thrombocytopenia, the number of platelets is less than $100,000 / \mathrm{mm}^{3}$; whereas, in immune thrombocytopenic purpura (ITP) and HELLP syndrome, it is definitely below this number. ${ }^{14}$ In this study, platelet numbers were compared between the two groups, and a significant difference was found.

Hepatic hemorrhage and hepatic rupture in HELLP syndrome are life-threatening complications and can be seen in approximately $0.5 \%$ of cases. The etiopathogenesis of this condition is not yet clear. However, histopathologic findings of the liver include intravascular fibrin deposits, which presumably lead to hepatic sinusoidal obstruction and intravascular congestion, and thus increase intrahepatic pressure causing hepatic necrosis, intraparenchymal and subcapsular hemorrhage, and capsular rupture. ${ }^{15,16}$ Increased hepatic enzymes reflect that the microcirculation in the liver is damaged, and as a result, its function is impaired. As found in this study, the fact that hepatic enzymes were increased, fibrinogen levels were decreased, and the coagulation parameter INR 
values were increased in the patient group with HELLP syndrome, clearly reveals that the hepatic microcirculation is impaired.

Hemolysis is one of the major features of HELLP syndrome and is due to microangiopathic hemolytic anemia. The damage of erythrocytes as a result of hemolysis causes an increase in lactate dehydrogenase (LDH). Therefore, the diagnosis of hemolysis can be made with high LDH and bilirubin levels. ${ }^{17}$

In HELLP syndrome, the characteristic change of the kidney is called glomerular capillary endotheliosis. This condition leads to a decrease in renal perfusion, glomerular filtration rate, uric acid, and creatinine clearance. ${ }^{18}$ In this study, the creatinine levels in the patient group were increased compared with the control group.

Preeclampsia disease spectrum/HELLP syndrome is one of the most common causes of intensive care requirement in obstetric patients. ${ }^{19-21}$ Making an early and differential diagnosis and providing appropriate management of the disease are important for maternal and fetal outcomes. Consequently, predicting HELLP syndrome based on these statements enables us to take the necessary precautions in these patients. When the literature is examined, PAPP-A and free $\beta$-HCG in the blood, ethnicity, nulliparity, previous preeclampsia and HELLP syndrome history, and mean arterial pressure values were found to be effective in predicting HELLP syndrome in the first trimester. ${ }^{22-24}$

This study is the first in the literature to investigate the role of first-trimester APRI scores in predicting HELLP syndrome.

\section{CONCLUSION}

APRi score is a non-invasive diagnose tool for the disease severity, especially in gastroenterological diseases. It can serve as an effective, practical, and useful method for predicting HELLP syndrome in the first trimester. APRI score in the first-trimester was a meaningful method for predicting HELLP syndrome with good sensitivity and specificity at a value of 0.55 .

\section{CONFLICT OF INTEREST:}

The authors declared no conflict of interest.

\section{ETHICAL APPROVAL:}

This study was conducted in compliance with the ethical principles according to the Declaration of Helsinki, and it was approved by the local Institutional Review Board (Approval No. 04-20/6).

\section{PATIENT'S CONSENT:}

Since it was designed as a retrospective study, the data were collected from the hospital archive after approval of the Ethics Committee.

\section{AUTHORS' CONTRIBUTION:}

HET: Data acquisition and analysis, interpretation, drafting, final approval.

NCK: Conception and design, interpretation, critical revision, final approval.

ENV: Design, critical revision, final approval.

YAR: Analysis and interpretation, drafting, final approval.

SC: Interpretation, critical revision, final approval.

ATC: Interpretation, critical Revision, final approval.

\section{REFERENCES}

1. Haram K, Svendsen E, Abildgaard U. The HELLP syndrome: Clinical issues and management. A Review. BMC Pregnancy Childbirth 2009; 9:8. doi: 10.1186/1471-2393-9-8.

2. Gasem T, Al Jama FE, Burshaid S, Rahman J, Al Suleiman SA, Rahman MS. Maternal and fetal outcome of pregnancy complicated by HELLP syndrome. J Matern Fetal Neonatal Med 2009; 22(12):1140-3. doi: 10.3109/147670509030 19627.

3. Oliveira N, Poon LC, Nicolaides KH, Baschat AA. First trimester prediction of HELLP syndrome. Prenat Diagn 2016; 36(1):29-33. doi: 10.1002/pd.4694.

4. Şaşmaz Mi, Ayvaz MA, Dülger AC, Kaykısız EKK, Güven R. Aspartate-aminotransferase to platelet ratio index score for predicting HELLP syndrome. Am J Emerg Med 2020; 38(3):459-62. doi: 10.1016/j.ajem.2019.02.014.

5. Gestational Hypertension and Preeclampsia: ACOG Practice Bulletin Summary, Number 222. Obstetrics \& Gynecology 2020; 135(6):1492-5. doi: 10.1097/AOG.000000000000 3892.

6. Barton JR, Sibai BM. Gastrointestinal complications of pre-eclampsia. Semin Perinatol 2009; 33(3):179-88. doi: 10.1053/j.semperi.2009.02.006.

7. Sibai BM, Ramadan MK, Usta I, Salama M, Mercer BM, Friedman SA. Maternal morbidity and mortality in 442 pregnancies with hemolysis, elevated liver enzymes, and low platelets (HELLP syndrome). Am J Obstet Gynecol 1993; 169(4):1000-6. doi: 10.1016/0002-9378(93)90043-i.

8. Barton JR, Sibai BM. Diagnosis and management of hemolysis, elevated liver enzymes, and low platelets syndrome. Clin Perinatol 2004; 31(4):807-33, vii. doi: 10.1016/j.clp.2004.06.008.

9. Dusse LM, Alpoim PN, Silva JT, Rios DR, Brandão AH, Cabral AC. Revisiting HELLP syndrome. Clin Chim Acta 2015; 451(Pt B):117-20. doi: 10.1016/j.cca.2015.10.024.

10. Wai CT, Greenson JK, Fontana RJ, Kalbfleisch JD, Marrero JA, Conjeevaram HS, et al. A simple noninvasive index can predict both significant fibrosis and cirrhosis in patients with chronic hepatitis C. Hepatology 2003; 38(2):518-26. doi: 10.1053/jhep.2003.50346.

11. Tseng CH, Chang CY, Mo LR, Lin JT, Tai CM, Perng DS, et al. Acoustic radiation force Impulse elastography with APRI and FIB-4 to Identify significant liver fibrosis in chronic hepatitis B patients. Ann Hepatol 2018; 17(5):789-94. doi: 10.5604/01.3001.0012.3137.

12. Sarkar J, DeLeon T, Wong LL. MELD score and AST-to-- 
platelet ratio index (APRI) predict long-term survival in patients with a small hepatocellular carcinoma following non-transplant therapies: A pilot study. Hepatoma Res 2017; 3:79-85. 10.20517/2394-5079.2017.06

13. Weinstein L. Syndrome of hemolysis, elevated liver enzymes, and low platelet count: a severe consequence of hypertension in pregnancy. 1982. Am J Obstet Gynecol 2005; 193(3 Pt 1):859; discussion 60. doi: 10.1016/ s0002-9378(16)32330-4.

14. Dusse LM, Rios DR, Pinheiro MB, Cooper AJ, Lwaleed BA. Pre-eclampsia: Relationship between coagulation, fibrinolysis and inflammation. Clin Chim Acta 2011; 412(1-2): 17-21. doi: 10.1016/j.cca.2010.09.030.

15. Norwitz ER, Hsu CD, Repke JT. Acute complications of preeclampsia. Clin Obstet Gynecol 2002; 45(2):308-29.

16. Kapoor S. Hepatic rupture: A rare but serious complication of HELLP syndrome. J Perinat Med 2014; 42(2):261-2. doi: 10.1515/jpm-2013-0238.

17. Baxter JK, Weinstein L. HELLP syndrome: the state of the art. Obstetrical \& Gynecol Survey 2004; 59(12):838-45. doi: 10.1097/01.ogx.0000146948.19308.c5.

18. Cunningham F, Gant N. leveno Leveno KJ, Glistrap L. C, Hauth JC, \& Wenstrom LD Williams Obstetrics. Newyork: McGrawhill. Medival Publishing division 2001;

19. Tran S, Fogel J, Karrar S, Hong P. Comparison of process outcomes, clinical symptoms and laboratory values between patients with antepartum preeclampsia, antepartum with persistent postpartum preeclampsia, and new onset postpartum preeclampsia. J Gynecol Obstetrics Hum Reprod 2020; 49(5):101724. doi: 10.1016/j.jogoh.2020. 101724.

20. Ebeigbe PN, Aziken ME. Early onset pregnancy-induced hypertension/eclampsia in Benin City, Nigeria. Niger J Clin Pract 2010; 13(4):388-93.

21. Leeners B, Neumaier-Wagner PM, Kuse S, Mütze S, RudnikSchöneborn S, Zerres K, et al. Recurrence risks of hypertensive diseases in pregnancy after HELLP syndrome. J Perinat Med 2011; 39(6):673-8. doi: 10.1515/jpm.2011.081.

22. Shekhar S, Diddi G. Liver disease in pregnancy. Taiwan J Obstet Gynecol 2015; 54(5):475-82.

23. Kaltofen T, Grabmeier J, Weissenbacher T, Hallfeldt K, Mahner S, Hutter S. Liver rupture in a 28-year-old primigravida with superimposed pre-eclampsia and hemolysis, elevated liver enzyme levels, and low platelet count syndrome. J Obstet Gynaecol Res 2019; 45(5):1066-70. doi: 10.1111/jog.13941.

24. Minakami H, Morikawa M, Yamada T, Yamada T, Akaishi R, Nishida R. Differentiation of acute fatty liver of pregnancy from syndrome of hemolysis, elevated liver enzymes and low platelet counts. J Obstet Gynaecol Res 2014; 40(3): 641-9. doi: 10.1111/jog.12282. 